Duguid, J. P. \& Wilknnson, J. F. (1953). J. gen. Microbiol. 9, 174-189.

\title{
The Influence of Gultural Conditions on Polysaccharide Production by Aerobacter aerogenes
}

\author{
By J. P. DUGUID and J. F. WILKINSON \\ The Bacteriology Department, University of Edinburgh
}

\begin{abstract}
SUMMARY: The polysaccharide content of Aerobacter aerogenes surface cultures grown on defined media was estimated by the anthrone method and related to the amount of growth as measured by the non-dialysable nitrogen content. Observations after different periods of incubation at $35^{\circ}$ showed that on a medium containing excess sugar, growth was complete after $24 \mathrm{hr}$. and polysaccharide production was complete after 4 days. While most of the polysaccharide was produced after the cessation of growth, the rate of production per cell was greatest in the logarithmic phase. The polysaccharide : nitrogen ratio was low in 4-day cultures on media wherein cessation of growth was due to exhaustion of sugar (the sole carbon and energy source) and also was low in growths limited by anaerobic conditions or by the development of acidity. It was increased 10-20-fold in cultures wherein cessation of growth was due to exhaustion of limited nitrogen, phosphorus or sulphur sources, so that an excess of sugar remained available for extra polysaccharide synthesis. This great increase in the polysaccharide: nitrogen ratio of the culture was paralleled by similar increases in the degree of mucoidness as measured by the wet weight:nitrogen ratio, in the intracellular polysaccharide content as measured by periodate-Schiff staining, in capsular polysaccharide as measured by capsule diameter, and in loose slime polysaccharide as measured chemically in the supernatant after centrifugation of the culture. After 4 days at $35^{\circ}$ the loose slime accounted for about half of the total polysaccharide in the highly mucoid cultures and about a fifth of that in the non-mucoid cultures.
\end{abstract}

The polysaccharides of bacteria can occur intracellularly, and extracellularly as capsules and loose slime. Intracellular polysaccharide is demonstrable microscopically by the specific periodate-Schiff staining method of Hotchkiss (1948) and McManus (1948) (Pennington, 1949; Bunting, Robinow \& Bunting, 1949; Lankford, Hoyo \& Lutteringer, 1951). Capsules and slime are demonstrable microscopically by a variety of methods, most satisfactorily in wet films with India ink (Duguid, 1951).

Previous investigations of the influence of cultural conditions on polysaccharide production by bacteria mostly have been made by methods which reveal only part of the polysaccharide. Birch-Hirschfeld (1936) extracted a polysaccharide-containing material from nutrient agar cultures of Salmonella paratyphi $\mathrm{B}$, and found greater amounts after growth at $25^{\circ}$ than at $37^{\circ}$. Morgan \& Beckwith (1939) observed the degree of mucoidness of surface cultures as indicative of the amount of capsule and slime; they found that a low temperature of incubation $\left(10-20^{\circ}\right)$ and the provision of readily utilizable carbohydrate were necessary for highly mucoid growth by salmonella and escherichia strains. Hoogerheide (1939) observed the viscosity of cultures in relation to their cell count and regarded this as a measure of capsule size. He found that the capsules of Klebsiella pneumoniae were 
largest in cultures at $37^{\circ}$ and that their size was determined by the amount of sugar supplied in a $4 \%$ peptone medium; the size was greatest with $1 \%$ glucose, increasing to a maximum after cessation of logarithmic growth; with less glucose it diminished latterly. In defined media capsules were largest when growth was limited by deficiency of phosphate, and very small when calcium was absent. Bukantz (1940) and Bukantz, Cooper \& Bullowa (1941) estimated the loose-slime polysaccharide (SSS) of type 3 pneumococci by measurement of the precipitate formed on addition of antiserum to the cell-free supernatant of a blood broth culture; most of the total SSS production occurred after cessation of logarithmic growth, but the rate of SSS production per cell was greatest in the early logarithmic phase and diminished progressively thereafter. Duguid (1948) measured microscopically in wet India ink films the capsules of $A$. aerogenes grown on defined media at $37^{\circ}$ for $24 \mathrm{hr}$.; capsules were largest on media having a high sugar: nitrogen or sugar: phosphorus ratio, wherein growth was limited by deficiency of the nitrogen or phosphorus source so that an excess of sugar, not consumed for growth, remained available for synthesis of capsular polysaccharide. Bunting et al. (1949) confirmed these findings for $A$. aerogenes and found that Chromobacterium prodigiosum behaved similarly; by periodate-Schiff staining they found that the cells having large capsules also had an unusually large intracellular polysaccharide content. Dagley \& Dawes (1949) estimated chemically the polysaccharide in centrifuged deposits of Bacterium coli cultures grown in defined media at $38^{\circ}$; the amount of polysaccharide at the end of growth varied with the sugar content of the medium; it diminished during the stationary phase regardless of whether nitrogen- or sugar-exhaustion had halted growth.

\section{METHODS}

Surface cultures of $\boldsymbol{A}$. aerogenes were prepared on agar media and measurements were made of their total polysaccharide content, and of the intracellular, capsular and slime fractions separately. The average capsule size and the degree of intracellular polysaccharide staining were observed microscopically. Chemical estimations were made on the deposits of centrifuged cultures for the intracellular and capsular polysaccharides combined, and on the supernatants for the slime polysaccharide. The amount of growth, i.e. of bacterial protoplasm formed, was assessed by a cell count, by an opacity measurement and by a non-dialysable nitrogen estimation. In addition to a visual assessment of the degree of mucoidness, a quantitative expression was obtained indicating the volume of the surface culture in relation to the volume of bacterial protoplasm within it; this was measured as the ratio of the wet weight of the culture to its nitrogen content.

Strains. The recorded observations were made with a single typical strain (A 3) of Aerobacter aerogenes. Parallel tests made with other strains of the species showed that these behaved similarly. Strain A 3 corresponded to Bact. aerogenes type 1 of Wilson (1935). It had the following properties: nonmotile; methyl-red negative; Voges-Proskauer positive; utilized citrate; 
indole negative; Eijkman negative; did not liquefy gelatine; fermented glucose, lactose, sucrose, mannitol, glycerol and inositol, but not dulcitol, producing acid and gas. It gave mucoid colonies on sugar-containing media such as MacConkey's agar, at $35-37^{\circ}$ and at $15-20^{\circ}$, and formed capsules on all cells together with much loose slime. It had been isolated from human faeces five years previously and thereafter maintained on nutrient agar.

Culture methods. Each surface culture was made on a disk of dialysis cellophan covering $50 \mathrm{ml}$. agar medium in a Petri dish of $9 \mathrm{~cm}$. diameter. The cellophan enabled rapid and complete removal of the culture for measurement of its wet weight and other estimations. The nutrient substances, lactose, ammonium sulphate and a phosphate mixture were added in various amounts to an agar base which contained per $100 \mathrm{ml}$. distilled water: washed agar powder, 2 g.; $\mathrm{NaCl}, 0.2$ g. $\mathrm{K}_{2} \mathrm{SO}_{4}, 0 \cdot 1$ g.; $\mathrm{MgSO}_{4} .7 \mathrm{H}_{2} \mathrm{O}, 0.02$ g. $; \mathrm{CaCl}_{2} .6 \mathrm{H}_{2} \mathrm{O}$, $0.002 \mathrm{~g}$. $\mathrm{FeSO}_{4}, 0.0001 \mathrm{~g}$. For tests of the influence of sulphate content, chlorides were substituted for the sulphates of ammonium, potassium, magnesium and iron, and the required amount of sodium sulphate added. Phosphate was used as a mixture at $\mathrm{pH} 7 \cdot 3$ of 3 parts by weight of $\mathrm{Na}_{2} \mathrm{HPO}_{4}$ and 1 part of $\mathrm{KH}_{2} \mathrm{PO}_{4}$; the amount of the phosphate supply is stated as the combined weight of the two salts. Most media contained $500 \mathrm{mg}$. phosphate/ $50 \mathrm{ml}$; this proved adequate as a buffer against any marked decrease in $\mathbf{p H}$ value resulting from fermentation. In tests of the influence of phosphate deficiency, where the phosphate content was $20 \mathrm{mg}$. or less $/ 50 \mathrm{ml}$., it was necessary to provide another buffer; 0.2 or $0.3 \%(w / v)$ sodium bicarbonate was incorporated in the medium and $25 \%(\mathrm{v} / \mathrm{v})$ carbon dioxide added to the air of the tank in which the culture was incubated; this $\mathrm{NaHCO}_{3}: \mathrm{CO}_{2}$ system was calculated to buffer at $\mathrm{pH} 7 \cdot 2-7 \cdot 4$. The agar base contained small amounts of 'contamination' nitrogen, phosphorus and sulphur compounds; the amount of these was indicated by the amount of growth obtained on medium with none of the corresponding nutrient added.

Disks of cellophan, $10 \mathrm{~cm}$. diameter (dry), were washea and sterilized by boiling in distilled water. With sterile forceps the moist disks were laid on the solidified agar plates so as to cover the whole surface of the agar and turn up at the dish edge. The inoculum was made from an overnight $35^{\circ}$ culture in $0.05 \%$ peptone water. A small loopful of this culture, containing about 300,000 cells, was spread over the whole upper surface of the cellophan so as to give a confluent film of growth on it. The plate was incubated with its lid ajar to allow free exchange of air. Thus open, each plate was incubated separately in a sealed glass tank of 81 . capacity. The 81 . air available to the $50 \mathrm{ml}$. plate was calculated to supply sufficient oxygen for complete aerobic utilization of the usual $250 \mathrm{mg}$. lactose content. An 18 l. tank was used for each of the few cultures made with $1000 \mathrm{mg}$. lactose $/ 50 \mathrm{ml}$. Incubation was either for 4 days at $35^{\circ}$ or for 14 days at room temperature $\left(15-20^{\circ}\right)$; preliminary tests had shown that these incubations were sufficient to allow virtual completion of growth and polysaccharide production.

Wet weight measurement. Immediately on removal of the plate from the tank after incubation, the cellophan disk together with the whole bacterial growth 
(moist but without free water) was stripped from the agar, folded up and placed in a weighing bottle; this was at once stoppered and weighed. The wet weight of the culture itself was obtained by subtracting the weight of the empty bottle plus $460 \mathrm{mg}$., which was the average weight of moist disks without cultures.

Degree of mucoidness. The appearance of the culture was noted and its degree of mucoidness recorded $(-,+,++,+++)$ according to how smooth and shiny the surface and how great the transparency in relation its depth on the cellophan.

Final $\mathrm{pH}$ value of medium. After removal of the disk carrying the culture, $5 \mathrm{ml}$. distilled water was poured on to the used agar medium and left for $1 \mathrm{hr}$. to allow diffusion of solutes from agar to water. The water was then decanted and its $\mathrm{pH}$ value determined by means of indicators.

Preparation of culture suspension. For the remaining estimations the culture was suspended in a buffered solution $\left(\mathrm{Na}_{2} \mathrm{HPO}_{4}, 0.0375 \mathrm{~g}\right.$.; $\mathrm{KH}_{2} \mathrm{PO}_{4}, 0.0125 \mathrm{~g}$.; $\mathrm{NaCl}, 0.2$ g.; $\mathrm{K}_{2} \mathrm{SO}_{4}, 0.1 \mathrm{~g}$; $\mathrm{MgSO}_{4} .7 \mathrm{H}_{2} \mathrm{O}, 0.02 \mathrm{~g}$; d distilled water, $100 \mathrm{ml}$; $\mathrm{pH} \mathrm{7 \cdot 3).} \mathrm{The} \mathrm{disk} \mathrm{with} \mathrm{the} \mathrm{culture} \mathrm{was} \mathrm{rubbed} \mathrm{into} \mathrm{successive} \mathrm{small} \mathrm{amounts}$ of solution on the bottom of a large beaker until the whole culture was uniformly suspended in $\mathbf{5 0 ~} \mathrm{ml}$.; much rubbing was needed for the highly mucoid cultures.

Average capsule diameter. Capsules were observed in wet films of culture suspension mixed with India ink (Duguid, 1951). The transverse capsule diameter, including the width of the bacillus and the capsular layers on both sides, was measured with an eyepiece micrometer. The average was taken of measurements of the first 50-100 bacilli found in selected parts of the film. From repeated observations it seemed that the error of estimation was less than $10 \%$ when the capsules were large and less than $20 \%$ when small. The width of the bacillus itself was about $0 \cdot 8 \mu$. and this should be subtracted from the recorded 'capsule diameter' to obtain the width of the capsular substance alone. The capsules were measured while suspended in a watery film and were thus somewhat expanded above their original size when in the less hydrated conditions of the surface culture (the expansion is seen microscopically when India ink is first added to solid culture material between slide and coverglass). The average bacillus length, disregarding the capsular layer, was estimated similarly.

Cell count. A portion of the culture suspension was killed with formalin and an appropriate dilution made. A loopful was placed on a Thoma type counting chamber of $0.02 \mathrm{~mm}$. depth and the bacilli counted by the $\frac{1}{6}$ in. dry objective of a phase contrast microscope. Four chamber preparations were counted for each culture and from the average count was calculated the total number of cells present in the whole culture (i.e. from $50 \mathrm{ml}$. culture medium).

Intracellular polysaccharide staining. Thick smears were fixed by flaming and stained by the periodate-Schiff method of Hotchkiss (1948), using the nonethanolic periodic acid ' $B$ ' solution and omitting the counterstain. The intensity of red-staining of the bacterial cytoplasm was observed microscopically, using a green filter, and was recorded on a scale ranging from the faintest, almost 
invisible staining $(+)$, through increasing intensities to a very dark red $(+$ to ++++$)$.

Opacity measurement. The opacity of the culture suspension was measured by the 'Spekker' photoelectric absorptiometer. The suspension was diluted when necessary to give a drum reading below $0 \cdot 40$, since below this value the relationship between number of bacteria and opacity reading is linear. The reading was multiplied by the dilution factor to express the opacity of the original culture suspension (i.e. culture from $50 \mathrm{ml}$. medium suspended in $50 \mathrm{ml}$. saline).

Preparation of culture fractions for chemical estimations. The major part of the culture suspension was centrifuged at 4000 r.p.m. for $30 \mathrm{~min}$. in an angle centrifuge. The deposit of bacterial cells and capsules was washed twice by resuspension in small amounts of saline and further centrifugation, and finally was suspended in $50 \mathrm{ml}$. fresh saline. The supernatants, which contained the slime, were combined and their volume measured. Before estimation of the polysaccharide, all monosaccharides and oligosaccharides were eliminated by dialysis (which also removed the dialysable nitrogenous substances such as ammonium salts and amino-acids). The culture deposits and supernatants were placed separately in bags of dialysis tubing. These were held in boiling water for $5 \mathrm{~min}$. to inactivate enzymes. The bags were then dialysed against distilled water for $40 \mathrm{hr}$. The volumes of the dialysed solutions were measured to ensure that they remained unchanged.

Chemical estimation of polysaccharide. Previous estimations of polysaccharide in bacteria have been made by methods depending on a lengthy hydrolysis followed by measurement of reducing value (e.g. Dagley \& Dawes, 1949). Recently, in the examination of yeasts, Trevelyan \& Harrison (1952) made use of the anthrone method which is more specific for polysaccharide and obviates the need for preliminary hydrolysis. The anthrone method, modified from Seifter, Dayton, Novic \& Muntwyler (1950), was used for the present study. We obtained greater reproducibility of results by adding the anthrone reagent slowly instead of rapidly; ten $1 \mathrm{ml}$. additions were made at 20 sec. intervals to $5 \mathrm{ml}$. amounts of test solution in tubes of similar size, these being shaken in a cold water bath. Preliminary hydrolysis was not used, since estimations made after hydrolysis with $2 \mathrm{~N}$-sulphuric acid at $100^{\circ}$ for periods up to $24 \mathrm{hr}$. did not give significantly increased values. A comparison was made batween this anthrone method and the method of hydrolysis for $20 \mathrm{hr}$. in $2 \mathrm{~N}$-sulphuric acid at $100^{\circ}$ followed by measurement of reducing value by the method of Somogyi (1945). Parallel estimations were made on non-mucoid and highly mucoid cultures grown respectively on medium containing $500 \mathrm{mg}$. peptone/ $50 \mathrm{ml}$. and medium containing $25 \mathrm{mg}$. peptone and $250 \mathrm{mg}$. lactose $/ 50 \mathrm{ml}$. The two methods gave similar polysaccharide values for the non-mucoid culture (polysaccharide: nitrogen ratios $\mathbf{1 . 0 4}$ and 1.1), but the anthrone method gave much higher values than the hydrolysis-Somogyi method for the mucoid culture (polysaccharide:nitrogen ratios 38 and 25 respectively). Although thus giving the higher values, the anthrone method still underestimates somewhat the true amount of polysaccharide; for instance, it does not reveal the 
uronic acid component. Estimations made in collaboration with $\mathrm{Mr}$ W. F. Dudman on extracted and purified polysaccharide from the strain A 3 of $A$. aerogenes suggested that the anthrone method reveals only about $65 \%$ of the total polysaccharide content. Nevertheless, the results of the estimations are recorded in terms of the anthrone value, as $\mathrm{mg}$. glucose equivalent/50 ml. culture.

Estimation of total non-dialysable nitrogen. The non-dialysable nitrogen content of the culture was determined by the micro-Kjeldahl method and recorded as $\mathrm{mg}$. N/50 ml. culture.

Dry weight estimation. A sample of the uncentrifuged culture suspension after dialysis was placed on a watch-glass and weighed after heating in an oven at $130^{\circ}$ for $3 \mathrm{hr}$. The result was recorded as $\mathrm{mg} . / 50 \mathrm{ml}$. culture.

\section{RESULTS}

\section{Influence of the nitrogen: sugar ratio in medium}

Cultures were grown aerobically for 4 days at $35^{\circ}$ on plates of $50 \mathrm{ml}$. agar medium containing $250 \mathrm{mg}$. lactose, $500 \mathrm{mg}$. of the phosphate mixture and different amounts of ammonium sulphate as sole added nitrogen source (the agar also contained contamination nitrogenous compounds equivalent in nutritional value to about $0.5 \mathrm{mg}$. ammonium sulphate/plate). The results of a typical experiment are given in Table $1(a)$.

The media with the large contents of ammonium sulphate (250 and $75 \mathrm{mg} . /$ $50 \mathrm{ml}$.) gave the maximum amount of growth supportable by their $250 \mathrm{mg}$. lactose content; utilization of the lactose apparently was complete and directed predominantly towards provision of energy for growth. This was confirmed by the results for cultures grown on a medium with $75 \mathrm{mg}$. ammonium sulphate and only $50 \mathrm{mg}$. lactose $/ 50 \mathrm{ml}$; t these cultures showed proportionate decreases in cell count and nitrogen content to about a fifth. Polysaccharide production was very small on the ammonia-rich media; the cultures appeared non-mucoid, their polysaccharide:nitrogen ratio, wet weight:nitrogen ratio and average capsule diameter were minimal and the cells showed very little intracellular polysaccharide by periodate-Schiff staining. The culture on $75 \mathrm{mg}$. ammonium sulphate and $250 \mathrm{mg}$. lactose $/ 50 \mathrm{ml}$. medium was near the lower limit of polysaccharide production, since the polysaccharide: nitrogen ratio $(\mathbf{1} \cdot 8)$ was little further diminished by increase of ammonium sulphate to $250 \mathrm{mg}$. or by decrease of lactose to $50 \mathrm{mg}$. (Table $1(a)$ ). This minimal polysaccharide production seemingly cannot be dispensed with in favour of greater provision of growth energy, however inadequate the supply of sugar.

The media containing $250 \mathrm{mg}$. lactose $/ 50 \mathrm{ml}$. with the smaller contents of ammonium sulphate $(25,7 \cdot 5,2 \cdot 5$ and $0.75 \mathrm{mg}$.) gave proportionately smaller amounts of growth as indicated by the cell count, opacity measurement and nitrogen content. The nitrogen contents of these cultures were nearly equal to the whole amount of the nitrogen available in the medium; this confirms that their growth was limited by exhaustion of the nitrogen supply. Such greatly decreased growths could not have required more than a small fraction 


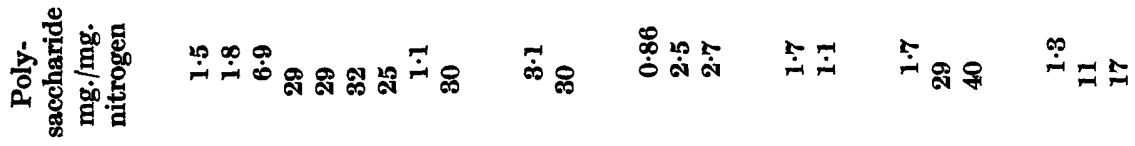

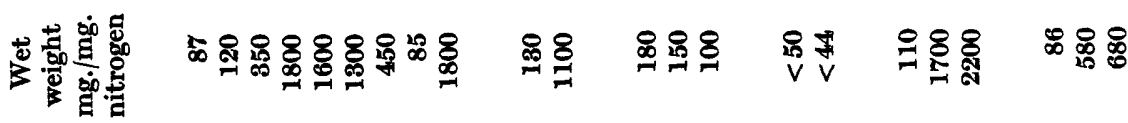
尊 密

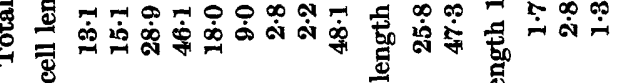

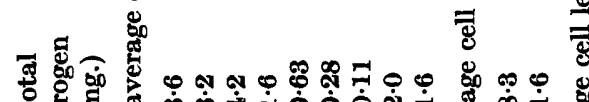

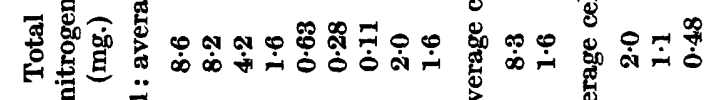

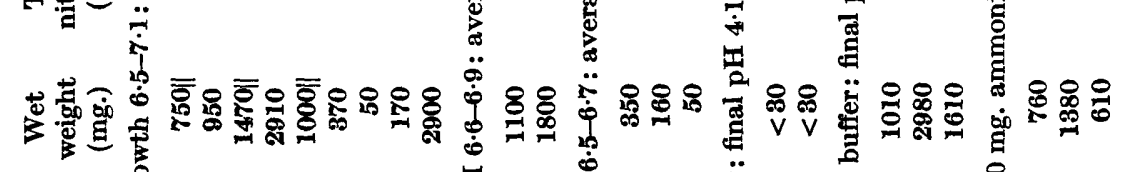

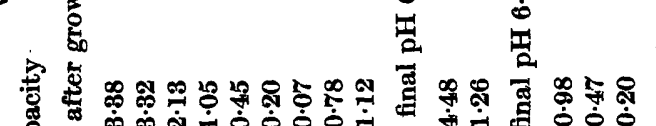

है

(1)

है

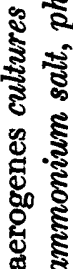

$\dot{4}$

3

है

这

w

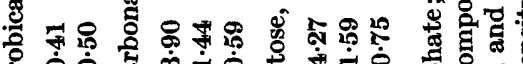

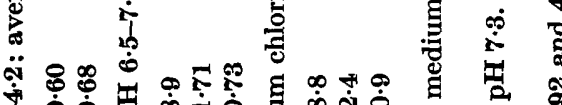

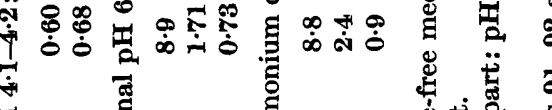

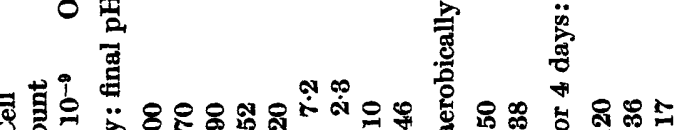

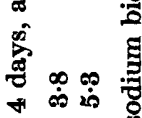
का

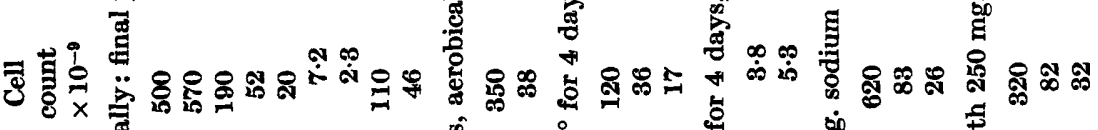

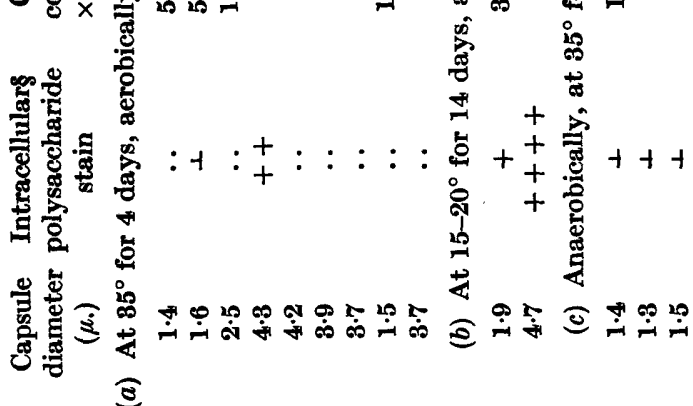

宽 छ

要 $\int \frac{1}{2}$ 88888888

$\circ 80$ i

ํำ

in

象

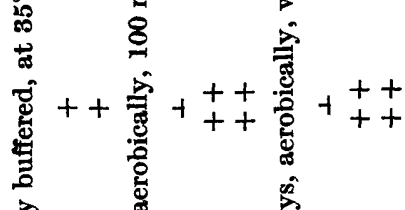

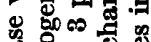

\% $* 8$

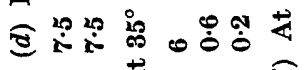


of the available lactose for provision of growth energy, and so must have retained a large excess available for extra polysaccharide synthesis. In fact, polysaccharide production was very great on the ammonia-poor media; the cultures were highly mucoid and their cells showed much intracellular polysaccharide by periodate-Schiff staining (Pl. 1, fig. 5); as compared with the ammonia-rich cultures, their polysaccharide : nitrogen and wet weight: nitrogen ratios were increased up to 20 -fold, and their average capsule diameter up to 3-fold. The culture on $7.5 \mathrm{mg}$. ammonium sulphate and $250 \mathrm{mg}$. lactose $/ 50 \mathrm{ml}$. was near to the upper limit of polysaccharide production, since its high polysaccharide:nitrogen ratio (29) was not exceeded significantly when the ammonium sulphate was decreased to $2.5 \mathrm{mg}$. or less, or when the lactose was increased to $1000 \mathrm{mg}$. (Table $1(a)$ ). Apparently there is an upper limit beyond which polysaccharide production does not continue, even when an abundance of unused sugar remains available. Production was not halted because of cell death; cell viability after growth for 4 days at $35^{\circ}$ was $90-100 \%$ in the ammonia-poor cultures and $70-80 \%$ in the ammonia-rich cultures.

Compared with the non-mucoid culture on $75 \mathrm{mg}$. ammonium sulphate and $250 \mathrm{mg}$. lactose $/ 50 \mathrm{ml}$., the mucoid culture on $7.5 \mathrm{mg}$. ammonium sulphate and $250 \mathrm{mg}$. lactose $/ 50 \mathrm{ml}$. gave only a fifth the amount of growth, as measured by the nitrogen content. Thus if the latter culture had produced relatively no more polysaccharide than the former (i.e. $3 \mathrm{mg}$., a fifth of $15 \cdot 1 \mathrm{mg}$.), it would have utilized for growth and polysaccharide synthesis only a fifth of the available $250 \mathrm{mg}$. lactose; about $200 \mathrm{mg}$. lactose was therefore available for production of the extra polysaccharide in the mucoid culture, namely $43 \mathrm{mg}$. in anthrone value. Since the actual polysaccharide content is about $1 \frac{1}{2}$ times the anthrone value, these results suggest that about $60 \mathrm{mg}$. polysaccharide was synthesized from $200 \mathrm{mg}$. lactose. The polysaccharide content, similarly corrected (anthrone value $\times 1 \frac{1}{2}$ ), composed about $20 \%$ of the dry weight of the non-mucoid culture on $250 \mathrm{mg}$. ammonium sulphate and about $60 \%$ of the dry weight of the mucoid culture on $2.5 \mathrm{mg}$. ammonium sulphate/50 ml. (Table $1(a)$ ).

The cultures grown with little ammonium sulphate $(7.5 \mathrm{mg}$. or less $/ 50 \mathrm{ml}$.) had twice as great a nitrogen content per cell, and thrice as great an opacity measurement per cell as the cultures made with much ammonium sulphate (250 or $75 \mathrm{mg}$. $/ 50 \mathrm{ml}$.). This was due in part to difference in cell size; measurements made on photomicrographs of wet films indicated that the average cell

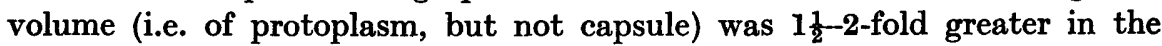
ammonia-poor cultures. The greater nitrogen content per cell in the ammoniapoor cultures was also due in part to the nitrogenous component of their more abundant capsules and slime.

In experiments made with peptone (Bactopeptone) as nitrogen source the results were similar to those obtained with ammonium sulphate. Cytological studies were made of cultures on $250 \mathrm{mg}$. lactose and $25 \mathrm{mg}$. peptone/ $50 \mathrm{ml}$. medium, which had large capsules and much slime. By the periodateSchiff method, strain $\mathrm{A} 3$ and most other $A$. aerogenes strains gave strong staining of their intracellular polysaccharide, but no visible staining of their 
capsules and slime (cf. Pl. 1, fig. 4); an exceptional strain, A 4, showed staining of the capsular polysaccharide in addition to the intracellular ( $\mathrm{Pl} .1$, fig. 2). Dried films, not shadowcast, were examined by the electron microscope. In most fields the bacillary outlines were obscured by dense shrunken capsular material, but in a few there was good differentiation. Thus Pl. 1, fig. 1 shows dark bacilli surrounded by lighter capsules, and these surrounded by still lighter slime. The capsules and slime appear continuous in substance, but are clearly demarcated by the difference in density. The slime continuum is fenestrated by shrinkage due to drying.

\section{Influence of the phosphate: sugar ratio}

Cultures were grown for 4 days at $35^{\circ}$ on plates of $50 \mathrm{ml}$. bicarbonatebuffered medium containing $250 \mathrm{mg}$. lactose, $250 \mathrm{mg}$. ammonium sulphate and different amounts of phosphate $\left(\mathrm{Na}_{2} \mathrm{HPO}_{4}, 3\right.$ parts by weight; $\mathrm{KH}_{2} \mathrm{PO}_{4}$, 1 part) as sole added phosphorus source (the agar also contained contamination phosphorus compounds equivalent in nutritional value to about $0.1 \mathrm{mg}$. phosphate $/ 50 \mathrm{ml}$.). The results for some typical cultures are shown in Table $1(e)$. The effect of phosphate limitation was similar to the effect of nitrogen limitation. The culture on $6 \mathrm{mg}$. phosphate/50 ml. medium gave maximal growth and minimal polysaccharide production; increase of phosphate supply to $20 \mathrm{mg}$. $/ 50 \mathrm{ml}$. did not further increase the amount of growth nor decrease the polysaccharide. The culture on $0 \cdot 2 \mathrm{mg}$. phosphate $/ 50 \mathrm{ml}$. gave a much smaller amount of growth and nearly maximal polysaccharide production, as indicated by a polysaccharide: nitrogen ratio of 40 . Further decrease of the phosphate supply did not give greater production of polysaccharide; e.g. a polysaccharide: nitrogen ratio of $\mathbf{3 6}$ was obtained in a lesser growth ( $0.20 \mathrm{mg}$. nitrogen content) given by a medium without added phosphate. Moreover, relatively little further increase of polysaccharide production resulted from a 4-fold increase of the lactose supply; a culture on $1000 \mathrm{mg}$. lactose and $0.2 \mathrm{mg}$. phosphate $/ 50 \mathrm{ml}$. medium showed a polysaccharide:nitrogen ratio of 48. The maximal polysaccharide production on phosphate-poor media was about $50 \%$ greater than the maximal on nitrogen-poor media. This difference was not due to the use of bicarbonate buffer in the phosphate-poor media; the nitrogen-poor media did not produce increased amounts of polysaccharide when buffered with bicarbonate and supplied with only $6 \mathrm{mg}$. phosphate $/ 50 \mathrm{ml}$. instead of $500 \mathrm{mg} . / 50 \mathrm{ml}$.

\section{Influence of the sulphate: sugar ratio}

Cultures were grown for 4 days at $35^{\circ}$ on plates of $50 \mathrm{ml}$. medium containing $250 \mathrm{mg}$. lactose, $250 \mathrm{mg}$. ammonium chloride, $500 \mathrm{mg}$. phosphate mixture and different amounts of sodium sulphate as sole added sulphur source (the agar also contained contamination sulphur compounds equivalent in nutritional value to about $0 \cdot 1 \mathrm{mg}$. sodium sulphate $/ 50 \mathrm{ml}$.). The results for three representative cultures are given in Table $1(f)$. Sulphate limitation was found to have a similar effect to nitrogen and phosphate limitations. Maximal 
growth and minimal polysaccharide production were obtained on the medium with $2 \mathrm{mg}$. sodium sulphate $/ 50 \mathrm{ml}$; a medium with the sulphate increased to $6 \mathrm{mg}$. $/ 50 \mathrm{ml}$. gave the same amount of growth and polysaccharide. Maximal polysaccharide production was obtained in the greatly decreased growth on medium without added sodium sulphate (i.e with 'contamination' sulphur compounds only). No further increase of polysaccharide was obtained by 4-fold increase of the lactose supply in this medium to $1000 \mathrm{mg}$. $/ 50 \mathrm{ml}$. The maximal polysaccharide production on the sulphate-poor media, as measured by the polysaccharide: nitrogen ratio (e.g. 17), was only about half the maximal on nitrogen-poor media.

\section{Influence of low temperature of incubation}

Cultures were grown for 14 days at room temperature $\left(15-20^{\circ}\right)$ on the phosphate-buffered lactose media containing different amounts of ammonium sulphate. The results for two representative cultures are shown in Table $1(b)$, and may be compared with the results for the corresponding cultures at $3^{\circ}$ shown in Table $1(a)$. The results for the two temperatures of incubation were generally similar. On a given medium the amount of growth as measured by the nitrogen content was the same at both temperatures. The $15-20^{\circ}$ cultures contained a smaller number of cells than the $35^{\circ}$ cultures, and these were slightly larger in size. The maximal polysaccharide production on the ammonia-poor media was the same at both temperatures, but the minimal production on the ammonia-rich media was almost twice as great at $15-20^{\circ}$ as at $35^{\circ}$. Thus, it is only in conditions of limited sugar and abundant nitrogen supply that a low temperature of incubation favours increase of mucoidness and polysaccharide production in $A$. aerogenes. The extent of such increase appears small compared with that observed by Birch-Hirschfeld (1936) and Morgan \& Beckwith (1939) for salmonella and escherichia strains. The 15-20 cultures on the ammonia-rich media gave higher opacity and dry-weight measurements than the corresponding $35^{\circ}$ cultures (e.g. dry weight $106 \mathrm{mg}$. as compared with $91 \mathrm{mg}$.); probably this was due to their higher polysaccharide content. The $15-20^{\circ}$ cultures yielded a greater proportion of their polysaccharide in the centrifuged cellular deposit and a smaller proportion in the supernatant; this was correlated with their slightly larger capsule size and their much greater intracellular polysaccharide content as shown by periodateSchiff staining (cf. Pl. 1, figs. 5 and 6).

\section{Influence of lack of oxygen}

Cultures were grown in an anaerobic jar for 4 days at $35^{\circ}$ on the phosphatebuffered lactose media containing different amounts of ammonium sulphate. The results for these cultures grown in the absence of molecular oxygen are shown in Table $1(c)$, and may be compared with those for the corresponding aerobic cultures shown in Table $1(a)$. The anaerobic culture on $250 \mathrm{mg}$. lactose and $75 \mathrm{mg}$. ammonium sulphate $/ 50 \mathrm{ml}$. had about the same cell count, nitrogen content and polysaccharide content as the aerobic culture on $50 \mathrm{mg}$. lactose and $75 \mathrm{mg}$. ammonium sulphate $/ 50 \mathrm{ml}$. Since growth on these ammonia-rich 
media was limited by the energy source, the result suggests that anaerobic utilization of the lactose yielded little more than a fifth of the energy obtainable aerobically.

The anaerobic cultures on the media with $250 \mathrm{mg}$. lactose and only 7.5 or $2.5 \mathrm{mg}$. ammonium sulphate $/ 50 \mathrm{ml}$. gave nearly as much growth as the aerobic cultures on the same media, but they did not give the very greatly increased polysaccharide production of the latter; their polysaccharide:nitrogen ratios little exceeded the minimum obtained in ammonia-rich cultures. The lactose supply in the ammonia-poor media under aerobic conditions constituted an excess providing for much extra polysaccharide synthesis, but under anaerobic conditions sufficed only for growth and a small polysaccharide production. It is possible that anaerobiosis is specifically unfavourable to polysaccharide synthesis, apart from its effect in decreasing the amount of energy obtainable from the sugar supply. This is suggested by the finding that the polysaccharide: nitrogen ratio was very little greater in the anaerobic culture on $2.5 \mathrm{mg}$. ammonium sulphate $/ 50 \mathrm{ml}$. than in that on $7.5 \mathrm{mg} . / 50 \mathrm{ml}$., in spite of there being available to the former more than twice as much sugar relative to the amount of growth.

\section{Influence of degree of acidity}

Cultures were grown for 4 days at $35^{\circ}$ on plates of $50 \mathrm{ml}$. medium containing $250 \mathrm{mg}$. lactose, large (75 mg.) or small (7.5 mg.) amounts of ammonium sulphate, and an amount of phosphate $(7.5 \mathrm{mg}$.) which was sufficient nutritionally for maximal growth, but quite inadequate as a buffer against development of an acid reaction from fermentation. The results are shown in Table $1(d)$, and may be compared with those for the corresponding well-buffered cultures in Table $1(a)$. The poorly buffered cultures became much more acid (e.g. pH 4.1) than the well-buffered cultures, and their growth was considerably less in amount. The bacilli composing the acid cultures were exceptionally large, with average length about four times that of the cells from the well-buffered cultures, and this was correlated with a larger nitrogen content per cell; they also differed from the normal bacilli in containing numerous granules of volutin.

The limitation of growth by acidity did not result in an increased production of polysaccharide; the polysaccharide:nitrogen ratio, wet weight:nitrogen ratio and capsule size were minimal. Furthermore, polysaccharide production was no greater in the acid culture on the ammonia-poor medium than in that on the ammonia-rich medium. Apparently an excess of energy source remained unutilized. It was therefore concluded that an acid reaction is inhibitory to polysaccharide synthesis, even at a $\mathrm{pH}$ value not low enough to prevent entirely the continuance of protoplasmic growth. If polysaccharide is required for septum formation, and thus for cell division, this might explain the abnormally long cells in acid cultures.

\section{Course of polysaccharide production during growth}

A series of cultures were grown on plates of $50 \mathrm{ml}$. nitrogen-poor medium containing $250 \mathrm{mg}$. lactose, $8 \cdot 3 \mathrm{mg}$. ammonium sulphate and $500 \mathrm{mg}$. phosphate 
mixture, and were incubated at $35^{\circ}$ for different periods ranging from 8 to $168 \mathrm{hr}$. The results for these separate cultures of different age are shown in Fig. 1. The phase of logarithmic growth extended approximately from 5 to $14 \mathrm{hr}$. (cell count $9 \cdot 6 \times 10^{9}$ and nitrogen content $0 \cdot 82 \mathrm{mg}$. at $14 \mathrm{hr}$.); thereafter growth continued at a decreasing rate until $24 \mathrm{hr}$., when the cell count

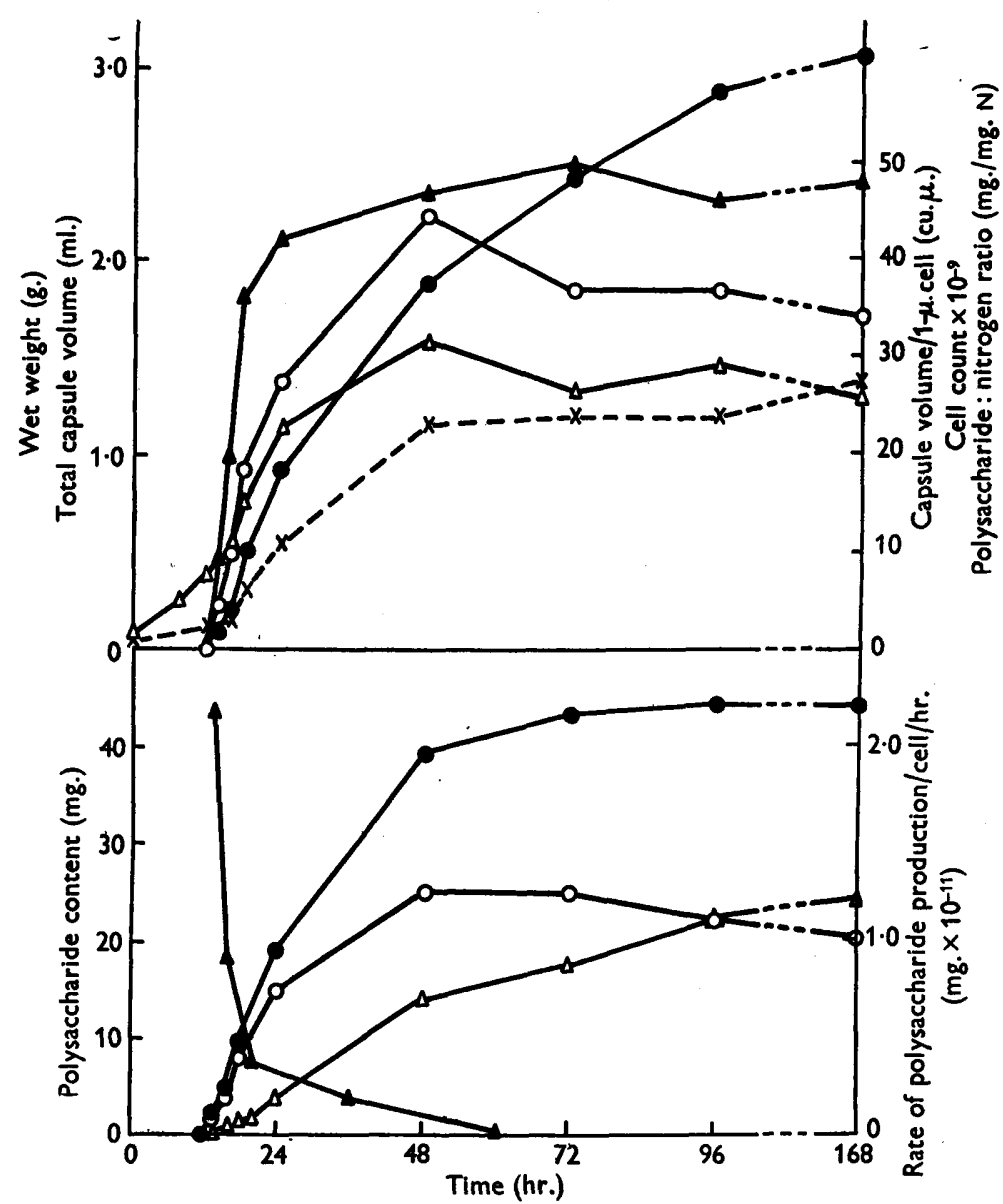

Fig. 1. Polysaccharide production, wet weight, capsule volume and cell count during growth on $50 \mathrm{ml}$. medium containing $250 \mathrm{mg}$. lactose and $8.3 \mathrm{mg}$. ammonium sulphate. Ordinates: (1) Top left; wet weight (g.), - - - - ; total capsule volume in suspension (ml.), -O-O-. (2) Top right: capsule volume/1- $\mu$. cell (cu. $\mu$.), $-\Delta-\Delta-$; cell count $\times 10^{-8},-\Delta-\Delta-$; polysaccharide : nitrogen ratio (mg./mg. $N$ ), $-x---\times-$. (3) Bottom left: total polysaccharide content (mg.), - i deposit polysaccharide content (mg.), $-\mathrm{O}-\mathrm{O}-$; supernatant polysaccharide content (mg.), $-\Delta-\Delta-$.

(4) Bottom right, rate of polysaccharide production/cell/hr. (mg. $\left.\times 10^{-11}\right),-\Delta-\Delta$.

$\left(42 \times 10^{9}\right)$ and nitrogen content $(1.7 \mathrm{mg}$.) were nearly maximal. Polysaccharide production occurred throughout the first 3-4 days of incubation, but the greater part of the polysaccharide (about $95 \%$ of the $44 \mathrm{mg}$. total) was produced after the end of the logarithmic phase; the main increase in the polysaccharide: nitrogen ratio (from $2 \cdot 3$ to 23 ) took place between 14 and $48 \mathrm{hr}$. 
However, the rate of polysaccharide production per cell was actually greatest during the logarithmic phase, and declined progressively thereafter. Fig. 1 shows this variation in the rate of total polysaccharide production/cell/hr. by A. aerogenes calculated according to the formulae used by Bukantz et al. (1941) for the rate of SSS production by pneumococci. The separate estimations for the culture deposits and supernatants showed that the main production of slime polysaccharide occurred later than the main production of intracellular and capsular polysaccharides; after $24 \mathrm{hr}$. the slime accounted for only c. $20 \%$ of the total polysaccharide, while after $96 \mathrm{hr}$. it accounted for $c .50 \%$.

On first becoming clearly visible after $12 \mathrm{hr}$. growth, the culture appeared non-mucoid, but acquired a highly mucoid character after $24 \mathrm{hr}$. The wet weight: nitrogen ratio increased throughout the 7 days to reach 1900 , but the main increase (from 110 to 1100) took place between 14 and $48 \mathrm{hr}$., concurrent with the main increase of polysaccharide. Intracellular polysaccharide staining was faint and uniform in the logarithmic phase (e.g. $\perp, \mathrm{Pl}$. 1, fig. 3), increased to a maximal intensity at $24-48 \mathrm{hr}$. (e.g.,+++ Pl. 1 , fig. 4) and then diminished, becoming faint in an increasing proportion of cells (e.g. ++ , at $96 \mathrm{hr} .$, Pl. 1, fig. 5). The average capsule diameter similarly increased during and after the logarithmic phase from the original size of $1.6 \mu$. to a maximum of $4 \cdot 3 \mu$. at $48 \mathrm{hr}$.; subsequently it diminished very slightly (e.g. $3.9 \mu$. at $168 \mathrm{hr}$.). The average volume of capsular material in cu. $\mu$. per standardized cell of $1 \mu$. length was calculated approximately as:

$$
\frac{1}{L}\left[\frac{4}{3} \pi R^{3}+\pi R^{2}(L-1)-\pi r^{2} L\right],
$$

where $\boldsymbol{R}=$ half the 'average capsule diameter', $r=$ bacillus radius (taken as 0.4 $\mu$. throughout), and $L=$ average bacillus length (e.g. $3.5 \mu$. at $8 \mathrm{hr}$. and $1.5 \mu$. at $18 \mathrm{hr}$.). The increase during growth of this average capsule volume $/ 1-\mu$. cell is shown in Fig. 1. Multiplication of this volume by the total cell count and average bacillus length gave the total capsule volume of the culture suspension. This latter provided the only measure obtainable of the total capsular polysaccharide exclusive of intracellular polysaccharide, and its increase during growth is shown in Fig. 1. In the first $48 \mathrm{hr}$. the calculated total capsule volume of the culture suspension was greater than the volume of the whole surface culture before suspension, measured by the wet weight converted to $\mathrm{ml}$.; presumably this was due to the capsular expansion which occurs on suspension in water. After $48 \mathrm{hr}$. the surface culture volume became the greater, presumably because of its increasing content of slime.

\section{DISCUSSION}

The present chemical estimations confirm and illustrate quantitatively the finding of Duguid (1948) that deficiency of nitrogen or phosphate greatly increases polysaccharide production by $A$. aerogenes. They show also that deficiency of sulphate acts likewise. This gives further support to the hypothesis that deficiency of an essential nutrient other than the carbohydrate source of energy, by limiting growth and thus the energy requirement for 
growth, conserves carbohydrate for synthesis of polysaccharide. Also in agreement was the finding that polysaccharide production was not increased when limitation of growth was achieved by decrease in the sugar supply or by exclusion of oxygen, the latter decreasing the amount of available energy from the given sugar supply. An upper limit was found to the amount of polysaccharide formed by cultures deficient in nitrogen-source, phosphate or sulphate; production was ended while the sugar and oxygen were unexhausted, the $\mathrm{pH}$ value favourable and most of the bacilli still alive. The factors responsible for this limitation are not known.

With varying conditions, the intracellular, capsular and slime polysaccharides generally increased or decreased together, though not in strict proportion. Thus, of the total polysaccharide content after 4 days at $35^{\circ}$, the slime comprised $35-63 \%$ in the highly mucoid cultures, but only $9-27 \%$ in the nonmucoid cultures. The proportion of slime polysaccharide in the $15-20^{\circ}$ cultures was only about half that in the $35^{\circ}$ cultures. The wet weight:nitrogen ratio proved a satisfactory measure of the degree of mucoidness; under all conditions it varied in concordance with the degree of mucoidness as judged visually, and also in close proportion with the polysaccharide: nitrogen ratio.

The best measure of the amount of protoplasmic growth proved to be the non-dialysable nitrogen content. Only a minor amount of non-dialysable nitrogenous matter seemed to occur extracellularly in the capsules and slime; between 1 and $20 \%$ of the total nitrogen was found in the supernatants, and another similar proportion may have been present in the capsules, though no separate measurement could be obtained of this. Thus it seems that little error is entailed in regarding the nitrogen content as a measure of the intracellular proteinous matter. The opacity and dry weight measurements were influenced too greatly by the polysaccharide content of the culture to serve as satisfactory measures of the amount of protoplasm. The cell count was misleading when the cell size was abnormal, as in the acid cultures.

It is generally recognized that in regard to the cytology, chemical constitution and metabolic activity of bacteria, a distinction must be made between the 'young' cells of the early logarithmic phase and the 'old' cells of the stationary phase. The present observations, with those made previously by staining for volutin and nuclear bodies (Duguid, 1948), indicate that in $A$. aerogenes a further distinction must be made of different types among the stationary-phase cells, these types differing according to the conditions which limit growth and initiate the stationary phase. First, the cells from cultures limited by exhaustion of the carbon and energy source are of the type generally considered 'normal', having normal length, small capsules and a low polysaccharide content. Secondly, the cells from cultures limited by exhaustion of the nitrogen-source, phosphate or sulphate are distinguished by their much larger capsules and polysaccharide content, and by the ease with which their nuclear bodies are revealed by simple staining; furthermore, the phosphatestarved cells are distinguished from the others by their habit of forming intracellular granules of volutin during the first hours of subcultivation on fresh medium containing phosphate. Thirdly, the cells from cultures limited 
by developing acidity are distinguished by their abnormally great length, their small capsules and polysaccharide content, and by their possession of numerous volutin granules.

The authors wish to express their thanks to Professor T. J. Mackie for his interest and encouragement.

\section{REFERENCES}

Birch-Hirschfeld, L. (1936). Zur Analyse der hydrophilen Kolloide in den Kolonien von Paratyphus B. Z. Hyg. InfektKr. 117, 626.

Bukantz, S. C. (1940). Relation between growth of Pneumococcus III and concentration of capsular polysaccharide appearing in culture filtrates. Proc. Soc. exp. Biol., N.Y. 43, 553.

Bukantz, S. C., Cooper, A. \& Bullowa, J. G. M. (1941). The elaboration of soluble capsular polysaccharide by Pneumococcus III in relation to growth phases in vitro. J. Bact. 42, 29.

Bunting, M. I., Robinow, C. F. \& Bunting, H. (1949). Factors affecting the elaboration of pigment and polysaccharide by Serratia marcescens. J. Bact. 58, 114.

Dagley, S. \& Dawes, E. A. (1949). Factors influencing the polysaccharide content of Escherichia coli. Biochem. J. 45, 331.

Duguid, J. P. (1948). The influence of cultural conditions on the morphology of Bacterium aerogenes with reference to nuclear bodies and capsule size. J. Path. Bact. 60, 265.

Duguid, J. P. (1951). The demonstration of bacterial capsules and slime. J. Path. Bact. 63, 673.

Hoogerheide, J. C. (1939). Studies on capsule formation. I. The conditions under which Klebsiella pneumoniae (Friedländer's bacterium) forms capsules. J. Bact. 38, 367.

Hoтchкiss, R. D. (1948). A microchemical reaction resulting in the staining of polysaccharide structures in fixed tissue preparations. Arch. Biochem. 16, 131.

Lankford, C. E., Hoyo, H. \& Lutteringer, J. F. (1951). Intracellular polysaccharide of Enterobacteriaceae. J. Bact. 62,621.

McManus, J. F. A. (1948). Histological and histochemical uses of periodic acid. Stain Tech. 23, 99.

Morgan, H. R. \& Beckwith, T. D. (1939). Mucoid dissociation in the colontyphoid-salmonella group. J. infect. Dis. 65, 113.

Pennington, D. (1949). The use of periodate in microbiological staining. J. Bact. $57,163$.

Seifter, S., Dayton, S., Novic, B. \& Muntwyler, E. (1950). The estimation of glycogen with the anthrone reagent. Arch. Biochem. 25, 191.

Somogy,, M. (1945). A new reagent for the determination of sugars. J. biol. Chem. $160,61$.

Trevelyan, W. E. \& Harrison, J. S. (1952). Studies in yeast metabolism. Biochem. J. 50, 298.

Wruson, G. S. (1935). The bacteriological grading of milk. Spec. Rep. Ser, med. Res. Coun., Lond. no. 206, p. 156.

\section{EXPLANATION OF PLATE}

Cultures of $A$. aerogenes on phosphate-buffered agar.

Fig. 1. Strain A 3. After $48 \mathrm{hr}$. at $35^{\circ}$ on lactose $250 \mathrm{mg}$. and peptone $25 \mathrm{mg} . / 50 \mathrm{ml}$. Unfixed and unshadowed film by electron microscope at $75 \mathrm{kv}$. Dark bacilli with lighter capsules surrounded by even lighter slime which is fenestrated by drying. $(\times 12,000$. 
Journal of General Microbiology, Vol. 9, No. 2
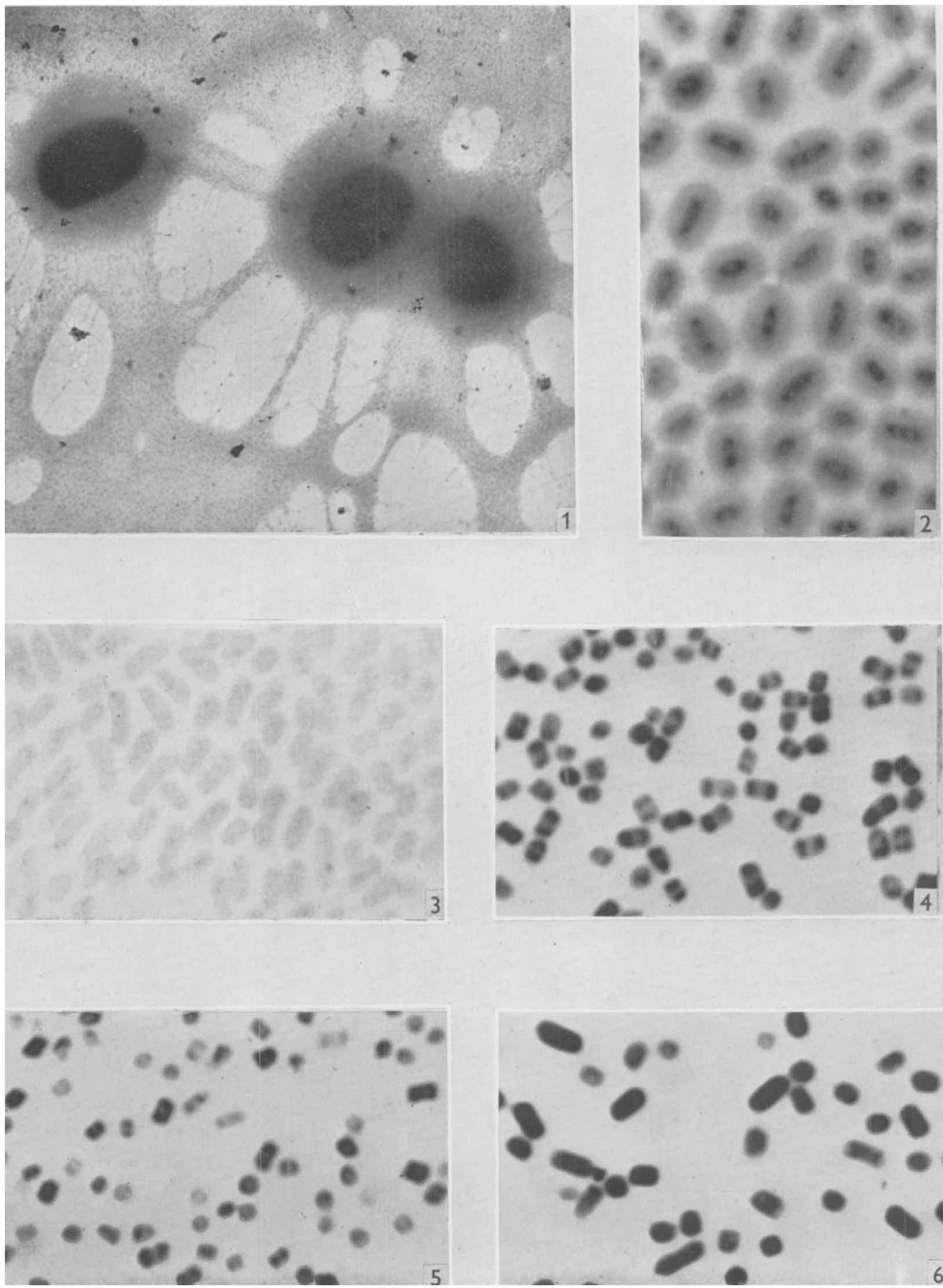

J. P. Duguid \& J. F. Wilkinson-Aerobacter aerogenes polysaccharides. Plate 1 
Fig. 2. Strain A 4. After $24 \mathrm{hr}$. at $35^{\circ}$ on lactose $250 \mathrm{mg}$. and peptone $25 \mathrm{mg} . / 50 \mathrm{ml}$. Periodate-Schiff stain for polysaccharide. Intense bipolar staining of cytoplasm and lighter staining of capsules. $(\times \mathbf{3 0 0 0}$.)

Figs. 3-6. Strain A 3. On lactose $250 \mathrm{mg}$. and ammonium sulphate $8 \cdot 3 \mathrm{mg} . / 50 \mathrm{ml}$. PeriodateSchiff stain. ( $\times 3000$.)

Fig. 3. After $10 \mathrm{hr}$. at $35^{\circ}$; slight uniform staining $(+)$.

Fig. 4. After $24 \mathrm{hr}$. at $35^{\circ}$; intense bipolar staining $(+++)$.

Fig. 5. After $96 \mathrm{hr}$. at $35^{\circ}$; intense staining in some cells and slight staining in others $(++)$.

Fig. 6. After 14 days at $15-20^{\circ}$; very intense staining $(++++)$.

(Received 17 February 1953) 